\title{
Glycolytic Enzymes from Human Neuroectodermal Tumors of Childhood
}

\author{
FRITS A. BEEMER,* ANNIE M. C. VLUG, $\dagger$ M. F. ROUSSEAU-MERCK, $\ddagger$ CEES W. M. VAN VEELEN, \\ GERT RIJKSEN $\dagger$ and GERARD E. J. STAAL $†$ \\ "University Children's Hospital "Het Wilhelmina Kinderziekenhuis" and Clinical Genetics Center, Utrecht, \\ The Netherlands, †Division of Medical Enzymology, Department of Hematology, State University Hospital, \\ Utrecht, The Netherlands, $\ddagger$ Hopital Necker, Paris, France and §Department of Neurosurgery, State University \\ Hospital, Utrecht, The Netherlands
}

\begin{abstract}
In this study pyruvate kinase, hexokinase and aldolase are investigated in two types of embryonal tumors, neuroblastomas and medulloblastomas; the results are compared with similar studies in gliomas. The activities of hexokinase and pyruvate kinase are significantly decreased in neuroblastomas. In neuroblastoma and medulloblastoma all five forms of pyruvate kinase $\left(K_{4}, K_{3} M\right.$, $K_{2} M_{2}, K M_{3}$ and $M_{4}$ ) are present. In contrast, the gliomas investigated are characterized by the presence of mainly $K_{4}$ and a little $K_{3} M$. In neuroblastomas, medulloblastomas and gliomas, hexokinase type $\mathrm{I}$ is present; in addition, hexokinase type II is present in two medulloblastomas. Aldolase $A$ is the predominant isozyme in all tumors investigated; this is in contrast with normal nervous tissue. It can be concluded that the isozyme characteristics especially of pyruvate kinase from neuroblastomas and medulloblastomas are comparable with similar findings in retinoblastoma; these findings support the hypothesis that these three tumors have a common embryonic origin.
\end{abstract}

\section{INTRODUCTION}

RECENTLY we presented the results of characterization of the glycolytic enzymes pyruvate kinase, hexokinase and aldolase from normal human retina (both fetal and adult) and retinoblastoma [1]. Retinoblastomas belong to the so-called embryonal neuroectodermal tumors [2]. Other embryonal tumors from neuroectodermal origin are neuroblastoma and medulloblastoma [3]. There is experimental support to the hypothesis that medulloblastoma is a stem cell neoplasm [2], just like neuroblastoma. There are remarkable histological similarities between neuroblastoma and retinoblastoma too, such as the so-called (pseudo-)rosettes [4].

It is well known that, as in other tumors [5-8], in brain tumors alterations in glycolytic enzymes can be found [9], especially in regulator enzymes such as pyruvate kinase and hexokinase. Fetal

Accepted 11 July 1983.

Correspondence and reprint requests to: Frits A. Beemer, University Children's Hospital "Het Wilhelmina Kinderziekenhuis", P.O. Box 18009, 3501 CA Utrecht, The Netherlands. brain is characterized by the presence of all five forms of pyruvate kinase $\left(K_{4}, K_{3} M, K_{2} M_{2}, K_{3}\right.$ and $\mathbf{M}_{4}$ ), whereas in poorly differentiated gliomas of adults mainly $\mathrm{K}_{4}$ and a little $\mathrm{K}_{3} \mathrm{M}$ are present [9] Retinoblastomas are characterized by the presence of all the forms except $\mathrm{M}_{4}$ [1]. This may be caused by a different embryological origin of these tumors. To give more evidence to this hypothesis, we investigated some glycolytic enzymes in neuroblastomas, medulloblastomas and gliomas of childhood. We compared the data with the results found earlier in another neuroectodermal tumor, i.c. retinoblastoma [1].

\section{MATERIALS AND METHODS}

Patients

Nine neuroblastomas (three classified as poorly differentiated neuroblastomas and six as more or less ganglioneuroblastomas) of eight patients, four medulloblastomas and eight gliomas of childhood were studied. The data of these patients are summarized in Table 1.

\section{Sample preparation}

Neuroblastomas, medulloblastomas and gliomas were stored immediately after surgery at 
Table 1. Data of the patients studied

\begin{tabular}{cccl}
\hline Patient number & $\begin{array}{c}\text { Age at diagnosis } \\
\text { (yr/months) }\end{array}$ & $\begin{array}{c}\text { Sex } \\
(\mathrm{M} / \mathrm{F})\end{array}$ & \multicolumn{1}{c}{ Histology } \\
\hline $\begin{array}{c}\text { Neuroblastoma } \\
1^{*}\end{array}$ & $5 /-$ & $\mathrm{M}$ & Neuroblastoma \\
$2^{*}$ & $6 /-$ & $\mathrm{M}$ & Neuroblastoma \\
3 & $-/ 3$ & $\mathrm{M}$ & Neuroblastoma \\
4 & -10 & $\mathrm{~F}$ & Ganglioneuroblastoma \\
5 & $\mathrm{l} / 4$ & $\mathrm{M}$ & Ganglioneuroblastoma \\
6 & $10 /-$ & $\mathrm{F}$ & Ganglioneuroblastoma \\
7 & $1 /-$ & $\mathrm{M}$ & Ganglioneuroblastoma \\
8 & $-/ 2$ & $\mathrm{M}$ & Ganglioneuroblastoma \\
9 & $6 /-$ & $\mathrm{M}$ & Ganglioneuroblastoma \\
Medulloblastoma & & & \\
1 & $5 / 3$ & $\mathrm{M}$ & Medulloblastoma (cerebellar) \\
2 & $5 / 4$ & $\mathrm{M}$ & Medulloblastoma (cerebellar) \\
3 & $7 / 1$ & $\mathrm{~F}$ & Medulloblastoma (cerebellar) \\
4 & $10 / 9$ & $\mathrm{~F}$ & Medulloblastoma (cerebellar) \\
Glioma & & & \\
1 & $7 / 2$ & $\mathrm{M}$ & Ependymoma \\
2 & $13 / 2$ & $\mathrm{~F}$ & Pilocytic astrocytoma \\
3 & $17 / 8$ & $\mathrm{~F}$ & Astrocytoma \\
4 & $5 / 2$ & $\mathrm{M}$ & Ependymoma \\
5 & $1 / 6$ & $\mathrm{~F}$ & Ependymoma \\
6 & $7 / 2$ & $\mathrm{M}$ & Ependymoma \\
7 & $6 / 7$ & $\mathrm{M}$ & Optic glioma \\
8 & $-/ 9$ & $\mathrm{~F}$ & Anaplastic glioma \\
\hline
\end{tabular}

Patient $1^{*}$ and $2^{*}$ is the same patient operated on two occasions.

$-70^{\circ} \mathrm{C}$. Tissues were homogenized by mincing one part with five parts of extraction buffer, containing $50 \mathrm{mM}$ Tris- $\mathrm{HCl}, \mathrm{pH} 8.0,0.1 \mathrm{M} \mathrm{KCl}$, $10 \mathrm{mM} \mathrm{MgCl}$, $2 \mathrm{mM}$ dithiothreitol and $0.1 \mathrm{M}$ sucrose. The mixture was rapidly minced (maximum duration $1 \mathrm{~min}$ in a pottermincer). After centrifugation at $15,000 \mathrm{~g}$ for $10 \mathrm{~min}$, the clear supernatant was used for the experiments; when the enzyme preparation was stored (at $-70^{\circ} \mathrm{C}$ ) sucrose was added up to a final concentration of $0.5 \mathrm{M}$ (storage had no influence on the enzyme activities and isozyme profiles).

\section{Electrophoresis}

Pyruvate kinase. The extracted enzymes were diluted to an activity of about $1.0 \mathrm{U} / \mathrm{ml}$ in the electrophoresis buffer containing $20 \mathrm{mM}$ Triscitrate ( $\mathrm{pH} 7.7$ ), $1 \mathrm{mM}$ fructose-1,6-diphosphate, $1 \mathrm{mM}$ disodium EDTA and $0.05 \mathrm{mM}$ dithiothreitol. Electrophoresis and staining for pyruvate kinase activity was carried out as previously described [10].

\section{Scanning of electropherograms}

The relative intensities of the bands in the electropherogram were quantitated at $540 \mathrm{~nm}$ with a densitometer (Helena Quickscan). The percentage of $\mathrm{K}$ - and $\mathrm{M}$-subunits, respectively, were calculated assuming: (a) a subunit distribution as indicated by the suffix in $K_{4}, K_{3} M, K_{2} M_{2}$, etc., and (b) equal contribution of $\mathrm{K}$ - and $\mathrm{M}$ subunits to the intensity of the stain.

Aldolase. Electrophoresis was performed on cellulose acetate in a $0.04 \mathrm{M}$ sodium-phosphate buffer ( $\mathrm{pH}$ 7.0). The gels were run at room temperature and $10 \mathrm{~V} / \mathrm{cm}$ during $1.5 \mathrm{hr}$. Staining and scanning was performed as previously described [1].

Hexokinase. Electrophoresis on cellulose acetate was carried out at $4^{\circ} \mathrm{C}$ and $20 \mathrm{~V} / \mathrm{cm}$ ( $\pm 2 \mathrm{~mA} / \mathrm{strip}$ ) during $45 \mathrm{~min}$ in a Tris-Veronal buffer (Gelman High-Resolution buffer) of pH 8.8 (I $0.05 \mathrm{~mol} / \mathrm{l}$ ) to which $2 \mathrm{mM}$ glucose, $0.05 \mathrm{mM}$ dithiothreitol and $1 \mathrm{mM}$ EDTA were added. Staining for hexokinase activity was carried out as previously described [1].

\section{Assay for glycolytic enzymes}

Glycolytic enzyme activities were determined by the methods of Beutler [3] at $37^{\circ} \mathrm{C}$ and expressed as $\mathrm{U} / \mathrm{mg}$ protein. The protein content was determined by the method of Lowry et al. [11] with crystalline bovine serum albumin as standard. Alanine inhibition of pyruvate kinase was determined as previously described [10].

\section{Chemicals}

Substrates and auxiliary enzymes for determination of enzyme activities were obtained from Boehringer Mannheim, F.R.G. All other chemicals were of the highest purity available. 


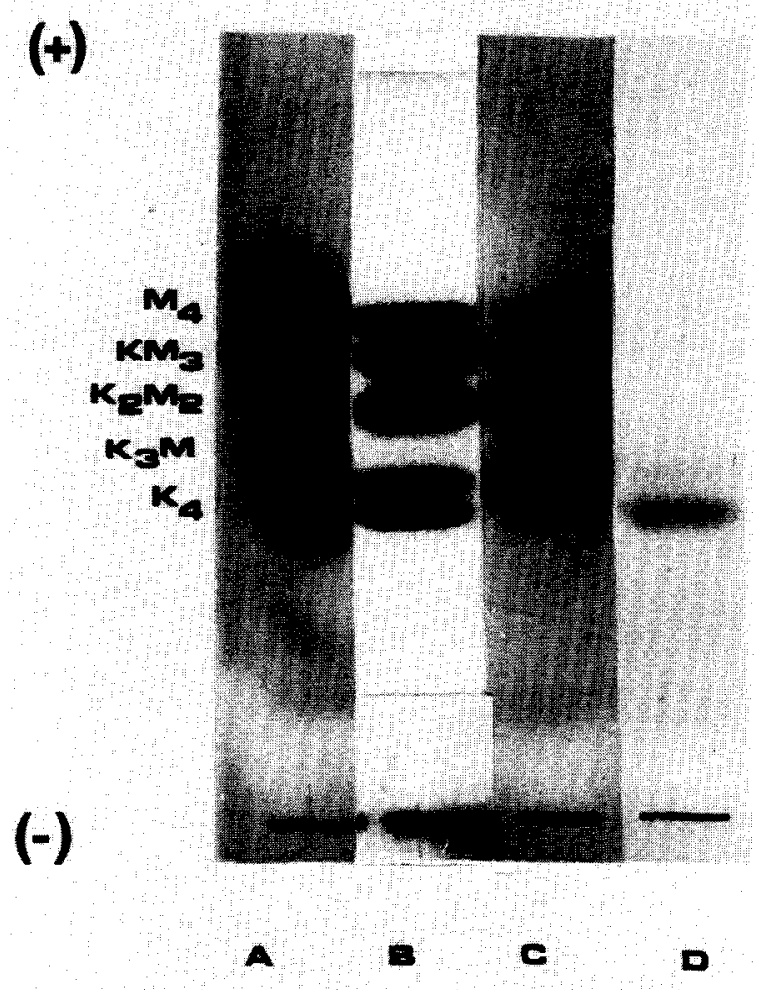

Fig. 1. Combined electrophoretic pattern of pyruvate kinase extracted from hypophysis $(A=$ reference $)$, neuroblastoma $(B)$, medulloblastoma $(C)$ and glioma $(D)$. 

. 


\section{RESULTS}

Enzyme activities

Table 2 summarizes the activities of some glycolytic enzymes from neuroblastomas $(n=9)$, medulloblastomas $(n=4)$ and gliomas of childhood ( $n=9$ ). Some activities of non-key enzymes of glycolysis in medulloblastomas, i.c. phosphoglucose isomerase, triosephosphate isomerase and enolase, are significantly increased with respect to neuroblastomas and gliomas. The activities of the key enzymes hexokinase and pyruvate kinase are significantly decreased in neuroblastomas. Within the group of ncuroblastomas no significant differences are found between the poorly differentiated neuroblastomas $(n=3)$ and the more differentiated ganglioneuroblastomas $(n=6)$. It should be noted that the activities shown in Table 2 concern only the cytosolic enzymes.

Pyruvate kinase. The isozymes of pyruvate kinase and their hybrids are according to Ibsen [12] designated as $\mathbf{M}_{4}, K_{3}, K_{2} M_{2}, K_{3} M$ and $K_{4}$. Figure 1 shows the electrophoresis of pyruvate kinase from one representative neuroblastoma, one medulloblastoma and one glioma. Neuroblastomas are characterized by the presence of all the five forms of pyruvate kinase $\left(\mathrm{K}_{4}, \mathrm{~K}_{3} \mathrm{M}, \mathrm{K}_{2} \mathrm{M}_{2}\right.$, $\mathrm{KM}_{3}$ and $\mathrm{M}_{4}$ ) and medulloblastomas show all forms also (little $\mathrm{K}_{4}$ ). In contrast, gliomas are characterized by mainly $\mathrm{K}_{4}$ and a little $\mathrm{K}_{3} \mathbf{M}$ [13] The percentages of $\mathbf{K}$ subunits are calculated from electropherograms by scanning (see Materials and Methods) and summarized in Table 3. Although neuroblastomas contain less $K$ subunits than medulloblastomas $(P<0.02)$, both are strikingly different from gliomas, in which $\mathrm{K}$ is by far the predominant subtype. The residual activities of pyruvate kinase in the presence of alanine are in good agreement with this observation (Table 3 ).

Neuroblastomas and medulloblastomas show relatively high residual pyruvate kinase activity in the presence of alanine, in contrast to the gliomas.

Hexokinase. Four isozymes of hexokinase are known, designated as I-IV in order of their increasing anodal electrophoretic mobility. The electrophoretic results of neuroblastomas, medulloblastomas and gliomas are summarized in

Table 2. Activity of glycolytic enzymes in neuroblastoma, medulloblastoma and glioma. The activities are expressed as $\mathrm{U} / \mathrm{mg}$ protein; the values are mean \pm S.D.

\begin{tabular}{llcc}
\hline \multicolumn{1}{c}{ Enzyme } & \multicolumn{1}{c}{$\begin{array}{c}\text { Neuroblastoma } \\
n=9\end{array}$} & $\begin{array}{c}\text { Medulloblastoma } \\
n=4\end{array}$ & $\begin{array}{c}\text { Glioma } \\
n=8\end{array}$ \\
\hline Hexokinase & $0.036 \pm 0.023(<0.02)$ & $0.077 \pm 0.042$ & $0.071 \pm 0.041$ \\
Phosphoglucose isomerase & $1.25 \pm 0.54$ & $2.69 \pm 0.48(<0.001)$ & $1.56 \pm 0.034$ \\
Aldolase & $0.069 \pm 0.048$ & $0.072 \pm 0.013$ & $0.065 \pm 0.023$ \\
Triosephosphate isomerase & $25.0 \pm 13.7$ & $73.8 \pm 63.5(<0.05)$ & 26.1 \\
Glyceraldehyde phosphate-dehydrogenase & $1.64 \pm 0.95$ & $1.91 \pm 1.32$ & $2.04 \pm 0.90$ \\
Phosphoglycerate kinase & $1.93 \pm 0.62$ & $3.04 \pm 1.61$ & $2.19 \pm 0.72$ \\
Enolase & $0.24 \pm 0.10$ & $0.52 \pm 0.20(<0.05)$ & $0.31 \pm 0.15$ \\
Pyruvate kinase & $1.26 \pm 0.84(<0.003)$ & $3.46 \pm 1.46$ & $3.02 \pm 1.41$ \\
\hline
\end{tabular}

The values in parentheses indicate the significance of the differences ( $P$-value, Student's $t$-test).

Table $3 A$. The percentage of $\mathrm{K}$ subunits and the residual activity of pyruvate kinase in the presence of alanine; values are mean \pm S.D.

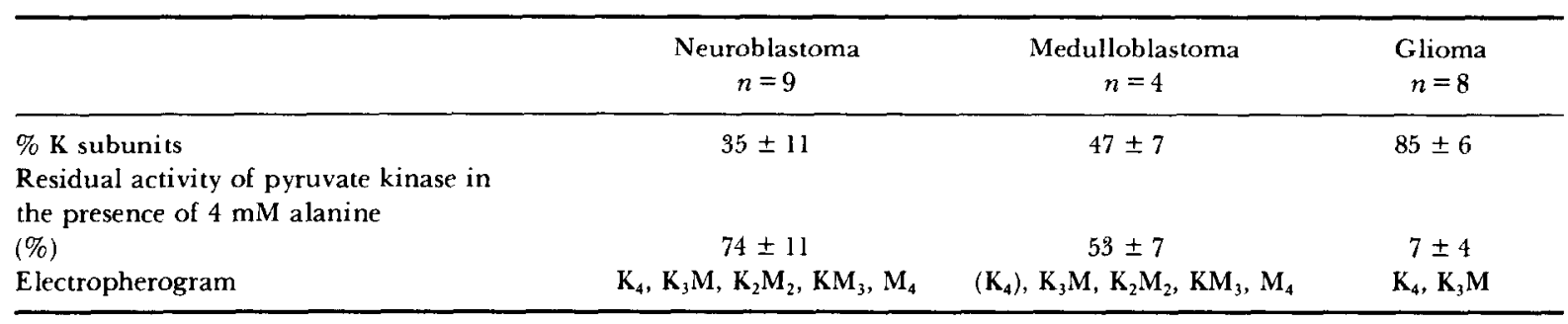

Table 3B. Hexokinase and aldolase isozyme distribution in neuroblastoma, medulloblastoma and glioma

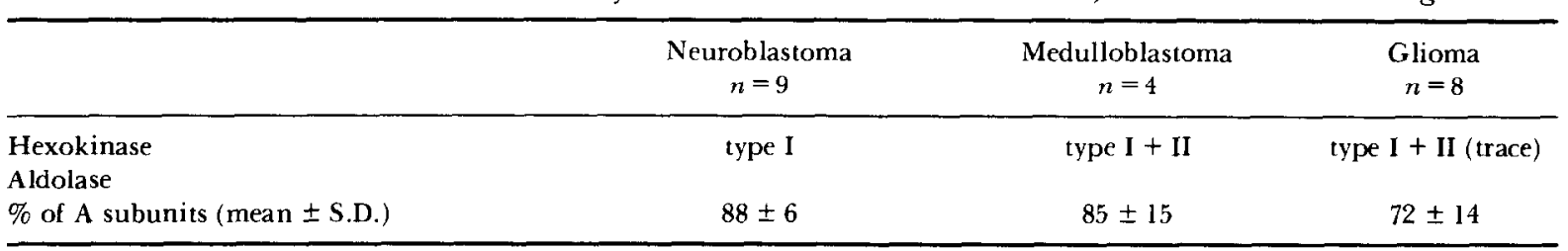


Table 3B. Neuroblastomas are characterized by the presence of hexokinase type I; little or no hexokinase type II could be detected. Medulloblastomas show besides hexokinase type I also type II in two of the four tumors investigated (17 and $57 \%$, respectively). The gliomas show a predominance of type I hexokinase and only a trace amount of hexokinase type II.

Aldolase. Three isozymes are known of this tetrameric enzyme. The isozyme $\mathrm{A}_{4}$ is predominant in adult skeletal muscle and most other tissues while the $\mathbf{B}_{4}$ isozyme is confined to the liver and kidney. Aldolase $\mathrm{C}_{4}$ is the principal form in nervous tissue. In this tissue, five hybrids of the $A$ and $C$ isozymes are found $\left(A_{4}, A_{3} C, A_{2} C_{2}, A C_{3}, C_{4}\right)$.

In contrast to normal nervous tissue, the main isozyme of aldolase in neuroblastomas and medulloblastomas as well as gliomas is the $A_{4}$ type. The percentage of $A$ subunits as calculated from densitograms are summarized in Table $\mathbf{3 B}$.

\section{DISCUSSION}

Recently we reported the characterization of pyruvate kinase, hexokinase and aldolase from normal fetal and adult retina and retinoblastoma [1]. In this papcr we report the characterization of the same enzymes from neuroblastomas, medulloblastomas and gliomas.

Neuroblastomas and medulloblastomas have much in common with retinoblastomas [4]. All three tumors show histological similarities, e.g. partial or complete rosette formation and more or less necrosis and calcification. All three types of tumors are characteristically childhood tumors and claimed to be of neuroectodermal origin [4]. Because of these common findings we compared the results of the enzymological investigations as found in retinoblastomas [1] with those in ncuroblastomas and medulloblastomas. We compared the results in these three neuroectodermal tumors as a whole with those found in gliomas of childhood, e.g. tumors of the supporting tissue of the central nervous system.

From the activities of the glycolytic enzymes shown in Table 2, one may conclude that differences exist between the three kinds of tumors. However, due to the large heterogeneity of the enzyme activities within the individual tumor groups, these differences are probably not of diagnostic value.

Secondly, we characterized the isozyme patterns of pyruvate kinase, hexokinase and aldolase in retinoblastomas, neuroblastomas and medulloblastomas as compared with gliomas of childhood. With respect to pyruvate kinase one may conclude that the observed isozyme pattern in neuroblastomas is similar to that in medulloblastomas and identical to that earlier found in retinoblastomas [1]. In neuroblastomas all potential five forms $\left(K_{4}, K_{3} M, K_{2} M_{2}, K_{3}\right.$ and $\left.M_{4}\right)$ are present as in medulloblastomas; the $M$ subunits are slightly predominant. This isozyme pattern is different from that in the gliomas of childhood (mainly $\mathrm{K}_{4}$ and a little $\mathrm{K}_{3} \mathrm{M}$, but no other forms) and from adults [9].

The residual activity of pyruvate kinase in neuroblastomas and medulloblastomas in the presence of alanine is comparable to that in retinoblastomas [1] and in striking contrast with the very low residual activity observed in the gliomas [13].

There is an ontogenic evolution of pyruvate kinase isozymes in brain. Van Veelen et al. [13] demonstrated that the $\mathrm{K}$-subunit is present in greater amounts in fetal than in adult human brain. With maturation a shift in isozyme composition occurs to an adult pattern in which $M_{4}$ is predominant with little or no $K_{4}$ and $K_{3} M$. In fetal human brain of 12 and 16 weeks, both type $\mathrm{M}$, type $\mathrm{K}$ and the three hybrids can be detected. The same pattern is found in neuroblastomas, retinoblastomas [1] and medulloblastomas. Therefore the pyruvate kinase isozyme distribution in these tumors resembles that found in fetal brain and fetal retina. For neuroblastomas, however, we cannot conclude that the observed isozymes pattern resembles that of the fetal tissues because we are not informed about the pyruvate kinase isozyme pattern of the tissue from which the tumors originate. Nevertheless the isozyme composition of pyruvate kinase in neuroblastomas, medulloblastomas and retinoblastomas is different from that found in gliomas of childhood.

In neuroblastomas and gliomas almost no hexokinase type II is found: type I is largely predominant. In medulloblastomas, type I and II are found, as was shown earlier in retinoblastomas. All three kinds of tumors show about the same isoenzyme pattern of aldolase. In contrast to normal nervous tissues, mainly the $\mathrm{A}_{4}$ isoenzyme and only small amounts of the other hybrids of the A-C set can be detected. As recently demonstrated [1], in retinoblastomas only $A_{4}$ aldolase is present, a pattern resembling the fetal retina. However, it is important to realize that both fetal brain and adult brain contain aldolase A $+\mathrm{C}$ mixed multimers, as was demonstrated by Hatzfeld and Schapira [14]. This may explain why the aldolase pattern of gliomas is identical to that of normal brain. Nevertheless the observed isozyme pattern of aldolase in neuroblastomas, medulloblastomas and retinoblastomas [1] is different from that found in gliomas.

It has been proposed by Weber $[6,7]$ that especially so-called regulator enzymes are altered 
in cancer. However, for aldolase, not being a regulator enzyme, isozyme changes in many tumors have been reported [5]. Therefore the findings regarding aldolase contradict Weber's concept. In conclusion, it appears that in neuroblastomas and medulloblastomas, the find ings common with retinoblastomas in clinical and histological respect may be extended with common findings in certain isozyme patterns.
This is especially the case for pyruvate kinase, which is a good marker for neuroectodermal tumors of childhood [15]. The observed electrophoretic pattern may be an expression of the stage of development.

Acknowledgements-We thank Mrs M. de Jong and E. L. Huisman-Backer Dirks for typing the manuscript.

\section{REFERENCES}

1. Beemer fa, Vlug amc, Rijksen G, Hamburg A, Staal gej. Characterization of some glycolytic enzymes from human retina and retinoblastoma. Cancer Res 1982,42 , $4228-4232$.

2. Palmer Jo, Kasselberg AG, NetSky MG. Differentiation of medulloblastoma. Studies including immunohistochemical localization of glial fibrillary acidic protein. J Neurosurg 1981, 55, 161-169.

3. BeUtler E. Red Cell Metabolism; a Manual of Biochemical Methods. New York, Grune \& Stratton, 1975, 38-70.

4. REESE AB. Retinoblastoma and other neuroectodermal tumors of the retina. In: Tumors of the Eye. Hagerstown, Maryland, Harper \& Row, 1976, Chapter 13.

5. SCHAPIRA F. Resurgence of fetal isozymes in cancer: study of aldolase, pyruvate kinase, lactic dehydrogenase and beta-hexosaminidase. In: RATTAZZI MC, SCANDALIOS JG, WHITT GS, eds. Isozymes: Current Topics in Biological and Medical Research. New York, Allan R. Liss, 1981, Vol. 5, 277-375.

6. WEBER G. Enzymology of cancer cells. I. N Engl J Med 1977, 196, 468-493.

7. WEBER G. Enzymology of cancer cells. II. $N$ Engl J Med 1977, 196, 541-551.

8. WEINHOUSE S. Metabolism of isozyme alterations in experimental hepatomas. Fed Proc $1973,32,2162-2167$.

9. VAN VEelen CWM, VERBIEST H, ZüLCH KJ et al. L- $\alpha$-Alanine inhibition of pyruvate kinase from tumors of the human central nervous system: a new aid in the treatment of gliomas. In: Brock M, ed. Modern Neurosurgery. Berlin, Springer Verlag, 1982, $110-121$.

10. VAN VEELEN CWM, RIJKSEN G, VLug AMC, STAAL GEJ. Correlation between alanine inhibition of pyruvate kinase and composition of K-M hybrids. Clin Chim Acta 1981, 110, 113-120.

11. LoWry OH, Rosebrough NJ, FARr AL, RANDALl RJ. Protein measurement with the Folin phenol reagent. $J$ Biol Chem 1951, 193, 265-275.

12. IBSEN KH. Interrelationships and functions of the pyruvate kinase isozymes and their variant forms: a review. Cancer Res 1977, 37, 241-253.

13. VAN Veelen CWM, Verbiest H, Vlug AMC, Rijksen G, StaAl GEJ. Isozymes of pyruvate kinase from human brain, meningiomas and malignant gliomas. Cancer Res 1978, 38, 4681-4687.

14. HatzFeld A, SChapira F. The ontogeny of aldolase in rat liver and brain. Biochimie $1973,55,53-57$.

15. Cottreau B, Rousseau-Merck MF, Nezelof C, Kahn A. Pyruvate kinase and phosphofructokinase isozymes in childhood cancer. Pediatr Res 1982, 16, 199-202. 